\title{
EFEKTIFITAS ASUHAN KEPERAWATAN DENGAN TERAPI AROMA LAVENDER DALAM MENGATASI INSOMNIA DI WILAYAH KERJA PUSKESMAS SEI PANAS BATAM
}

\author{
${ }^{1}$ Larasuci Arini, ${ }^{2}$ Juanita \\ Institut Kesehatan Mitra Bunda \\ Email:larasuci.arini78@gmail.com
}

\begin{abstract}
ABSTRAK
Program kesehatan di semua kalangan usia, salah satu adalah program untuk lansia ini bertujuan untuk meningkatkan UHH (usia harapan hidup) pada lansia yaitu mengupayakan agar para lansia menikmati masa tua bahagia dan berguna, memfokuskan pada upaya promotif dan preventif, adanya peran serta aktif dan partisipasi lintas sektor, puskesmas sebagai kunci utama dalam pergerakan masyarakat di harapkan melakukan upaya pro aktif berkerja sama dengan tokoh masyarakat untuk meningkatkan kesejahteraan lansia. Insomnia adalah gangguan tidur yang sering dikeluhkan lansia yang ditandai dengan kesulitan untuk tidur dan mempertahankan tidur. Insomnia pada lansia disebabkan oleh beberapa faktor, yaitu dari faktor status kesehatan, penggunaan obat-obatan, kondisi lingkungan, stres psikologis, diet/nutrisi, gaya hidup pada usia lanjut. Aromaterapi merupakan salah satu terapi komplementer yang dapat digunakan untuk mengatasi insomnia. Aromaterapi memiliki efek menenangkan atau rileks untuk beberapa gangguan misalnya mengurangi kecemasan, ketegangan dan insomnia. Tujuan pelaksanaan asuhan keperawatan ini adalah agar lansia dapat mengatasi insomnia yang dialami secara non farmakologis menggunakan aroma terapi lavender. Metode dari penelitian ini adalah studi kasus yang menggunakan asuhan keperawatan meliputi pengkajian, diagnosa, intervensi, implementasi dan evaluasi. Hasil dari pemberian asuhan keperawatan ini adalah dengan pemberian terapi aroma lavender selama 30 menit, pasien merasa rileks saat akan tidur, sehingga dianggap mampu mengatasi insomnia. Berdasarkan hasil pemberian asuhan ini aroma terapi lavender merupakan salah satu terapi non farmakologis yang dianggap efektif untuk mengatasi insomnia pada lansia. Pada penelitian ini diharapkan pada keluarga dan masyarakat menggunakan terapi aroma terapi sebgai alternatif mengatasi insomnia.
\end{abstract}

Kata kunci : Lansia, insomnia, terapi aroma, lavender.

\section{ABSTRACT}

Health programs for all ages, one of which is a program for the elderly which aims to increase UHH (life expectancy) in the elderly, namely making the elderly enjoy a happy and useful old age, focusing on promotive and preventive efforts, active participation and participation. Across sectors, health centers as the main key in community movement are expected to make pro-active efforts to work together with community leaders to improve the welfare of the elderly. Insomnia is a sleep disorder that is often complained of by the elderly, characterized by difficulty sleeping and maintaining sleep. Insomnia in the elderly is caused by several factors, namely health status, drug use, environmental conditions, psychological stress, diet / nutrition, lifestyle in the elderly. Aromatherapy is a complementary therapy that can be used to treat insomnia. Aromatherapy has a calming or relaxing effect for several disorders such as reducing anxiety, tension and insomnia. The purpose of implementing this nursing care is so that the elderly can overcome insomnia experienced nonpharmacologically using lavender aroma therapy. The method of this research is a case study that uses nursing care including assessment, diagnosis, intervention, implementation and evaluation. The result of this nursing care provision is by giving lavender aroma therapy for 30 minutes, the patient feels relaxed when going to sleep, so that he is considered able to overcome insomnia. Based on the results of this care, lavender aroma therapy is one of the non-pharmacological therapies that is considered effective for treating insomnia in the elderly. In this study, it is expected that families and communities use aromatherapy as an alternative to treat insomnia.

Key words: Elderly, insomnia, aroma therapy, lavender. 


\section{PENDAHULUAN}

Lanjut Usia adalah suatu proses yang dialami yang tidak dapat di hindari oleh manusia. Lansia di tandai dengan perubahan Fisik, Emosional, dan kehidupan seksual. Gejala-gejala kemunduran Fisik seperti merasa cepat sesak, stamina menurun, badan membengkok, kulit keriput, rambut memutih, gigi mulai rontok, fungsi panca indra menurun, dan pengapuran pada tulang rawan. (Maramis, 2016).

Stanhope dan Lancaster (2016) mengungkap- kan bahwa risiko biologi termasuk risiko ter- kait usia pada lanjut usia yaitu terjadinya ber- bagai penurunan fungsi biologi akibat proses menua. Risiko sosial dan lingkungan pada lan- jut usia yaitu adanya lingkungan yang memicu stres. Aspek ekonomi pada lansia yaitu penu- runan pendapatan akibat pensiun. Risiko peri- laku atau gaya hidup seperti dan konsumsi ma- kanan yang tidak sehat dapat memicu terjadi- nya penyakit dan kematian.

Kebutuhan fisiologis adalah kebutuhan yang dasar, paling kuat dan paling jelas dari antara sekalian kebutuhan manusia adalah kebutuhannya untuk mempertahankan hidupnya secara fisik, yaitu kebutuhannya akan makanan, minuman, eliminasi, seks, oksigen dan tidur. (Maslow 2012)

Insomnia adalah gangguan tidur yang sering dikeluhkan lansia yang ditandai dengan kesulitan untuk tidur dan mempertahankan tidur. Insomnia pada lansia disebabkan oleh beberapa faktor, yaitu dari faktor status kesehatan, penggunaan obat-obatan, kondisi lingkungan, stres psikologis, diet/nutrisi, gaya hidup pada usia lanjut (Bandiyah, 2012). Insomnia pada lansia juga dihubungkan dengan penurunan memori, konsentrasi terganggu dan perubahan kinerja fungsional. Perubahan yang sangat menonjol yaitu terjadi penurunan gelombang alfa dan meningkatnya frekuensi terbangun di malam hari atau meningkatnya fragmentasi tidur karena seringnya terbangun (Laraswati,2014)
Aroma wangi yang ditimbulkan dari lavender dipercaya mempunyai efek yang sensitive terhadap sistem limbik di otak, dimana bagian tersebut berhubungan dengan emosional dan memori pada manusia. Molekul yang dilepaskan ke udara adalah sebagai uap air. Ketika uap air yang mengandung komponen kimia tersebut dihirup, akan diserap tubuh melalui hidung dan paru-paru yang kemudian masuk ke aliran darah. Uap aromaterapi dihirup, molekul uap tersebut akan berjalan mempengaruhi sistem limbik otak yang bertanggung jawab dalam sistem integrasi dan ekspresi perasaan, belajar, ingatan, emosi, rangsangan fisik, serta memberikan perasaan rilek sehingga memberikan lingkungan tidur yang nyaman (Nuraini, 2014)

Seiring dengan hasil penelitian Reni, (2018) Aromaterapi merupakan salah satu terapi komplementer yang dapat digunakan untuk mengatasi insomnia. Aromaterapi memiliki efek menenangkan atau rileks untuk beberapa gangguan misalnya mengurangi kecemasan, ketegangan dan insomnia.

Menurut Cuncic, 2013:3 Aroma terapi terdiri dari minyak tumbuhan atau minyak esensial untuk meningkatkan kesejahteraan psikologis. Aromaterapi dianjurkan untuk orang yang memiliki masalah untuk menenangkan tubuh, pikiran dan saraf. Wewangian seperti lavender digunakan untuk relaksasi terutama mengurangi susah tidur.

Appleton, 2013 mengatakan Aromaterapi lavender adalah aroma terapi yang menggunakan minyak esensial dari bunga lavender, dimana memiliki komponen utama berupa Linalool dan Linali Asetat yang dapat memberikan efek relaksasi. Berdasarkan uraian masalah diatas, maka rumusan masalah penelitian asuhan keperawatan ini adalah Efektifitas Asuhan Keperawatan Dengan Terapi Aroma Lavender Dalam Mengatasi Insomnia di Wilayah Kerja Puskesmas Sei Panas Batam 


\section{METODE PENELITIAN}

Desain penelitian ini adalah merupakan rancangan studi kasus dengan menerapakan asuhan keperawatan meliputi pengkajian, diagnosa, intervensi, implementasi, dan evaluasi. Penelitian ini dilakukan di wilayah kerja Puskesmas Sungai Panas kota Batam. Penelitian ini dilakukan selama 7 hari dengan metode kunjungan pada satu pasien. Selama proses penelitian ini menggunakan media dan alat seperti format asuhan keperawatan, lavender oil, dan alat penguap.

\section{HASIL DAN PEMBAHASAN}

Pada tanggal 02 Desember 2019 dilakukan pengkajian pada Ny. Usia 60 tahun, beragama Islam dengan status perkawinan adalah kawin, pendidikan terkahir Ny. $\mathrm{Y}$ adalah SMA dengan perkerjaan sebagai Ibu Rumah Tangg. Saat pengkajian didapatkan data : kesadaran klien composmentis, wajah Ny. Y tampak lemas, tampak mata klien sayu, tanpak klien menguap sesekali, jumlah tidur klien 3-4 Jam setiap malam dengan kualitas tidur tidak nyenyak, Sering terbangun pada malam hari dan sulit untuk kembali tidur. klien tampak gelisah, klien selalu bertanya tentang penyakitnya, ekspresi wajah tampak tegang, TTV : TD : 150/100 $\mathrm{mmHg}$, Nadi : $88 \mathrm{x} /$ menit, Suhu : $36,5 \circ \mathrm{C}, \mathrm{RR}: 20$ $\mathrm{x} /$ menit. Klien mengatakan stress karna beban pikiran tentang anak-anaknya, klien mengatakan tidak mengkonsumsi obat tidur, tampak terlihat jelas kantung mata pasien dan hitam disekitaran bawah mata.

Keluhan yang disampaikan oleh $\mathrm{Ny}$. $\mathrm{Y}$ tersebut sesuai dengan tanda dan gejala insomnia menurut Amirta (2009), Yaitu Kebanyakan orang dewasa membutuhkan antara tujuh dan delapan jam setiap malam dan tanda gejala yang biasa muncul klien merasa lelah saat bangun tidur dan tidak merasa kesegaran. Penderita insomnia sering merasa tidak tidur sama sekali padahal kita sering melihat mereka memejamkan mata. Berapa banyak tidur yang dibutuhkan tubuh bervariasi dari satu orang ke orang lain. Gejala insomnia biasanya berlangsung satu minggu dianggap insomnia sementara. Gejala berlangsung antara satu dan tiga minggu dianggap insomnia jangka pendek dan gejala penguat lebih dari tiga minggu diklasifikasikan sebagai insomnia kronis.
Orang yang menderita insomia biasanya terus berpikir tentang bagaimana untuk mendapatkan lebih banyak tidur, semakin mereka mencoba, semakin besar penderitaan mereka dan menjadi frustrasi yang akhirnya mengarah pada kesulitan yang lebih besar.

Diagnosa keperawatan yang dijumpai dalam masalah yang didapatkan adalah Gangguan Pola Tidur Berhubungan Dengan ketidakmampuan mengatasi stres yang dialami ditandai dengan susah tidur, kualitas tidur tidak nyenyak, sulit untuk memulai tidur, sulit untuk melanjutkan tidur jika sudah terbangun. Pada saat pagi hari klien merasa tubuhnya tidak merasa segar dan badan terasa sakit-sakit saat bangun tidur, jika sedang banyak pikiran klien tidak bisa tidur. Klien mengatakan sudah mengalami susah tidur sudah sejak dari lama \pm 3 bulan. Sedangkan data Objektif yang mendukung yaitu: Wajah Ny. Y tampak lemas, Sesekali Menguap, Jumlah tidur klien 3-4 Jam setiap malam, sering terbangun pada malam hari, klien mengatakan tidurnya kurang puas, TD : $150 / 100 \mathrm{mmHg}$, Nadi : $88 \mathrm{x} /$ menit, Suhu : $36,5 \circ \mathrm{C}, \mathrm{RR}: 20 \mathrm{x} / \mathrm{menit}$. Masalah yang kedua adalah Ansietas berhubungan dengan perubahan status kesehatan yang ditandai dengan klien mengatakan merasa cemas dengan keadaannya, klien mengatakan tidak nyaman. Sedangkan data objektif yang mendukung yaitu : klien tampak gelisah, klien selalu bertanya tentang penyakitnya, ekspresi wajah tampak tegang, klien tanpak kurang berkonsentrasi saat diajak berbicara.

Diagnosa ini sesuai dengan teori dimana tanda dan gejala atau respon tubuh yang mengalami insomnia menurut nanda NIC NOC (2015). Yaitu insomnia disebabkan oleh berbagai masalah antara lain masalah psikologis, lingkungan, aktifitas, kuantitas tidur harian, faktor genetis, fisiologis, konsumsi makanan tertentu, dan kenyamanan. Faktor psikologis yang menyebabkan insomnia adalah ansietas, cemas, depresi, ketakutan, berduka, dan stres. Selain faktor psikologis, faktor lingkungan juga mempengaruhi kejadian insomnia. Lingkungan yang bising, cahaya yang terang atau gelap, suhu yang ekstrim, kelembaban lingkungan, dan tatanan yang 
tidak familiar mengganggu pola tidur seseorang. Selain itu,kuantitas tidur yang tidak sesuai seperti susah tidur siang dan tidur malam yang terputus juga dapat mengganggu pola tidur seseorang, konsumsi alkohol, kebersihan diri yang tidak terjaga dengan baik, konsumsi obat, ketidaknyamanan fisik seperti nyeri, batuk, mual, inkontinensia, dan urgensi juga menyebabkan insomnia.

Intervensi Keperawatan yang dilakukan sesuai dengan tugas perawatan yang pertama yaitu mengenalkan masalah dengan cara mengkaji permasalahan insomnia kepada klien. Mendiskusikan permasalahan insomnia kepada klien. Selanjutnya memberitahukan dampak dari insomnia. Menjelaskan pada klien definisi aromaterapi lavender. Menjelaskan pada klien manfaat aromaterapi lavender, kaji pola tidur klien, diskusikan pada klien kemungkinan faktor lain yang menyebabkan gangguan pola tidur, memeriksakan vital sign klien, dan menganjurkan klien untuk menerapkan aromaterapi lavender sebelum tidur.

Intervensi yang telah dilakukan ada kesamaan yang sesuai dengan teori yang diterapkan dari NANDA NIC NOC (2015), yang dimana diagnosanya adalah Gangguan Pola Tidur Berhubungan Dengan Faktor Eksternal Ditandai Dengan Susah Tidur, Tidur Tidak Nyenyak, Dan Wajah Tampak Tidak Segar, Pantau pola tidur pasien dan catat hubungan faktorfaktor fisik (misalnya, apnea saat tidur, sumbatan jalan nafas, nyeri/ketidaknyamanan, dan sering berkemih) atau faktor-faktor psikologis misalnya, ketakutan, atau ansietas yang dapat mengganggu pola tidur pasien

Terapi yang digunakan untuk penderita insomnia ada beberapa terapi yang bisa digunakan salah satunya adalah pemberian aromaterapi lavender. Aromaterapi lavender yang dilakukan oleh klien sesuai dengan teori yang diterapkan oleh Jaelani (2009), aromanya dihirup selama menit 15-30 menit. Selain aromaterapi lavender, ada beberapa terapi yang bisa digunakan untuk permasalahan insomnia yang diantaranya adalah , terapi otot progesif, brain gym, dan mandi air hangat.
Implementasi dari diagnosa Gangguan pola tidur berhubungan dengan ketidakmampuan mengatasi stres yang dialami ditandai dengan susah tidur, tidur tidak nyenyak, dan wajah tampak tidak segar.Ny $Y$ bisa mengenalkan dengan baik masalah dari permasalahan insomnia klien. Dapat mengetahui permasalahan insomnia klien. Selanjutnya klien dapat mengetahui dampak dari insomnia. Klien dapat memahami defenisi, tujuan dan manfaat dari penerapan aromaterapi lavender.

Implemetasi dari diagnosa ini sesuai dengan hasil penelitian berdasarkan penelitian yang dilakukan oleh Rini 2016 Prevalensi Insomnia di Indonesia pada lansia cukup tinggi,yaitu sebesar $67 \%$. Penuaan dapat mengubah pola tidur seseorang. Pada usia sekitar 50 tahun, mulai terjadi penurunan gelombang tidur sehingga pada usia tua kuantitas tidur yang dalam pada seseorang akan berkurang. Sehingga penting dari aromaterapi lavender menjadi peran penting guna untuk memberikan solusi kepada klien yang mengalami permasalahan insomnia ini.

Penelitian ini sejalan dengan penelitian yang dilakukan oleh Dian (2018) dengan judul Pengaruh aromaterapi lavender terhadap kualitas tidur lansia di wisma cinta kasih didapatkan Hasil penelitian menunjukkan bahwa Aroma terapi lavender dapat meningkatkan kualitas tidur lansia

Berdasarkan penelitian yang dilakukan oleh Yeni (2015) dengan judul pengaruh pemberian lavender aromatherapy terhadap penurunan insomnia pada lanjut usia di upt panti werdha mojopahit mojokerto didapatkan hasil yaitu ada pengaruh pemberian lavender aromatherapy terhadap penurunan insomnia sebelum dan setelah pemberian aromaterapi lavender

Hal tersebut sejalan dengan penelitian yang dilakukan oleh Diah (2015) dengan judul pengaruh aroma terapi lavender (lavandula Angustifolia) terhadap insomnia pada lansia banjar tangtu puskesmas II denpasar timur didapatkan hasil yaitu adanya pengaruh terhadap pemberian aromaterapi lavender. 
Evaluasi dari diagnosa keperawatan ini berdasarkan intervensi NANDA NIC NOC (2015) dilakukan selama 6 hari mulai dari tanggal 02 Desember - 07 Desember 2019 didapatkan pada hari pertama tanggal 03 desember 2019 hasil subjektif yaitu Ny. Y mengatakan tidur 3-4 jam pada malam hari, sering terbangun pada malam hari tanpa sebab, klien mengatakan tidak merasa puas dengan tidurnya, klien mengatakan jika sedang banyak pikiran tidak bisa tidur, klien mengatakan tidak bisa tidur pada siang hari, ketika dilakukan observasi oleh penulis, keadaan umum baik, klien tanpak lemas, klien paham penyebab dari masalah gangguan tidurnya, mata klien tanpak sayu, tanpak klien menguap sesekali, tanpak terlihat jelas kantung mata klien dan disekitaran mata berwarna kehitaman, hasil tanda-tanda vital: TD : 150/100 $\mathrm{mmHg}$, Nadi: 88x/menit, RR: $20 \mathrm{x} /$ menit, Suhu: $36,5 \circ \mathrm{C}$

Pada hari kedua tanggal 03 Desember 2019 hasil subjektif yaitu klien mengatakan tadi malam tidur masih terbangun dan tidak bisa tidur kembali, klien mengatakan tidak ada tidur pada siang hari, hasil observasi pada Ny. Y yaitu wajah klien tanpak lelah, mata klien tanpak sayu, masih terlihat jelas kantung mata klien dan disekitaran mata kehitaman, iris warna hitam, konjungtiva tidak anemis , TD: 140/80 mmHg, Nadi:80 $\mathrm{x} /$ menit, RR: $19 \mathrm{x} /$ menit, suhu: $36,3{ }^{\circ} \mathrm{C}$.

Pada hari ketiga tanggal 04 Desember 2019 hasil subjektif pada Ny. Y yaitu klien mengatakan tidur tadi malam tidak sulit untuk memulai tidur namun masih ada terbangun dan sulit untuk tidur kembali, klien mengatakan tidur dengan aromaterapi lavender dan sedikit rileks dengan wewangiannya, hasil observasi pada Ny. Y yaitu wajah klien masih tanpak lelah, klien sudah mulai bisa untuk berkonsentrasi saat diajak bicara, masih tanpak menguap sesekali, wajah klien tanpak tidak segar, klien bisa sedikit mengontrol stress yang dialami , TD: 140/80 mmHg, Nadi: 85 $\mathrm{x} /$ menit, RR: $20 \mathrm{x} / \mathrm{menit}$, Suhu: $36,5^{\circ} \mathrm{C}$.

Pada hari keempat tanggal 05 Desember 2019 dengan hasil subjektif yaitu klien mengatakan tadi tidak sulit untuk memulai tidur, namun masih terbangun pada malam hari dan sulit untuk tidur kembali, klien mengatakan tidur selama 5 jam pada malam hari, klien mengatakan kualitas tidur sedikit nyenyak, hasil observasi pada $\mathrm{Ny}$. Y yaitu wajah klien sedikit segar, kantung mata klien tidak terlalu jelas, klien tidur 5 jam pada malam hari, klien tanpak sedikit rileks dan klien mampu mengontrol stress yang dialami, TTV: TD :130/90 mmHg, RR: $20 \mathrm{x} /$ menit, Suhu : 36,6 $\circ$ C.

Pada hari kelima pada tanggal 06 Desember 2019 , dengan hasil subjektif pada Ny. $Y$ yaitu klien mengatakan tadi malam tidak sulit untuk memulai tidur, klien mengatakan tidur selama 5 jam pada malam hari, kualitas tidur klien sedikit nyenyak, klien mengatakan dapat tidur siang selama 1 jam, hasil observasi pada Ny. Y yaitu wajah klien tanpak segar, klien tanpak sedikit rileks dan klien mampu mengontrol stress yang dialami, TTV : TD: 130/80 mmHg, Nadi: 85 x/menit, RR: 20 $\mathrm{x} /$ menit, S: 36,7॰C.

Pada hari keenam pada tanggal 07 Desember 2019 dengan hasil subjektif pada Ny. $\mathrm{Y}$ yaitu klien mengatakan tadi malam tidak sulit untuk memulai tidur, klien mengatakan tadi malam tidur selama 6 jam ,klien mengatakan tidurnya tadi malam nyenyak,klien mengatakan sedikit rileks karna aromaterapi lavender, klien mengatakan ada tidur siang namun hanya 1 jam, hasil observasi pada $\mathrm{Ny}$. $\mathrm{Y}$ yaitu wajah klien tanpak segar, masih tanpak ada kantung mata, klien tidur selama 6 jam pada malam hari, klien tanpak rileks dan bisa mengontrol stress yang dialaminya, mata klien tanpak segar, TTV: TD: 120/80 mmHg, Nadi : 78 x/menit, RR: $21 \mathrm{x} /$ menit, Suhu: $36,4 \circ \mathrm{C}$.

Terapi pemberian aromaterapi lavender untuk mengatasi insomnia pada Ny. $\mathrm{Y}$ yang dilakukan selama 6 hari pada tanggal 02 Desember 2019 sampai dengan 07 desember 2019 didapatkan hasil pada Ny. $Y$ yaitu adanya perubahan dalam kualitas tidur. Ny. Y diberikan aromaterapi lavender dengan cara inhalasi, aromaterapi lavender ini menggunakan tungku yang diisi air sebanyak $75 \mathrm{ml}$ dan teteskan minyak essensial 6-7 tetes, lalu hidupkan lilin dibawah tungku dan hirup uap aromaterapi lavender Selama 15-30 menit aromaterapi lavender yang digunakan mengandung 
bahan utama dari ekstrak tanaman lavender, senyawa utamanya adalah linalool (51\%) dan linalyl asetat (35\%). Kedua senyawa ini dapat masuk kesistem saraf melalui indra penciuman, sistem pernafasan dan kulit.

Berdasarkan jurnal penelitian yang dilakukan oleh Dian (2018) dengan judul pengaruh aromaterapi lavender terhadap kualitas tidur lansia di wisma cinta kasih, peneliti menggunakan aromaterapi dengan teknik inhalasi yang di hirup selama 30 menit. Peneliti melakukan penelitian selama 7 hari . pada penelitian ini peneliti menunjukkan hasil perubahan kualitas tidur di hari ketujuh

Sama halnya dengan jurnal penelitian yang dilakukan oleh Yeni (2015) dengan judul pengaruh pemberian lavender aromatherapy terhadap penurunan insomnia pada lanjut usia di upt pati werdha mojopatit mojokerto, peneliti membutuhkan waktu 7 hari, peneliti menggunakan aromaterapi lavender dengan cara inhalasi yang dihirup selama 15-30 menit. pada penelitian ini ditunjukkan hasil perubahan dihari ketujuh.

Berbeda dengan jurnal penelitian yang dilakukan oleh Diah (2015) dengan judul pengaruh aroma terapi lavender (lavandula Angustifolia) terhadap insomnia pada lansia banjar Tangtu puskesmas ii denpasar timur. Pada penelitian ini peneliti menggunakan aromaterapi dengan teknik inhalsi, peneliti membutuhkan waktu 2 minggu. Peneliti menggunakan aromaterapi dengan inhalasi yang dihirup selama 30 menit. Peneliti menunjukkan hasil perubahan di minggu kedua

\section{KESIMPULAN}

Asuhan keperawatan diberikan pada klien dari tanggal 02-08 Desember 2019, penulis dapat membuat kesimpulan pada saat pengkajian keperawatan didapatkan klien mengatakan dirinya sulit untuk mulai tidur pada malam hari, kadang tidurnya hanya 34 jam saja sering terbangun pada malam hari. Jika sudah terbangun dari tidur maka akan sulit untuk tidur kembali. Dan pada saat pagi hari klien merasa tubuhnya tidak merasa segar dan badan terasa sakit-sakit. Klien mengatakan jika klien sedang banyak pikiran klien tidak bisa tidur. Klien mengatakan sudah mengalami susah tidur sudah sejak dari lama \pm 3 bulan. Klien mengatakan merasa cemas dengan kondisinya saat ini. TTV : TD: 150/100 $\mathrm{mmHg}$, Nadi : $88 \mathrm{x} /$ menit, suhu: $36,5 \circ \mathrm{C}$, $\mathrm{RR}$ : 20x/menit, diagnosa keperawatan terhadap klien didapat ditegakkan dua diagnosa utama, yakni: Gangguan pola tidur berhubungan dengan ketidakmampuan mengatasi stres yang dialami ditandai dengan susah tidur, tidur tidak nyenyak, dan wajah tampak tidak segar. Diagnosa kedua, yakni : Ansietas berhubungan dengan kurang terpapar informasi ditandai dengan gelisah, kurang berkonsentrasi, berkeringat dan bertanya tentang penyakitnya.

Intervensi keperawatan yang di berikan klien yang dilakukan pendampingan, penjelasan, pengajaran tentang penerapan aromaterapi lavender. Diberikan juga penjelasan tentang defenisi, faktor yang mempengaruhi insomnia, dan penatalaksanaan untuk mengatasi insomnia. Dan klien bersedia menjadi responden dan mau menerapkan aromaterapi lavender dalam mengatasi masalah insomnianya.

Di dalam melakukan implementasi keperawatan pada klien harus diakui adanya faktor yang mendukung pelaksanaan namun juga ada faktor yang menghambat pelaksanaannya. Faktor pendukungnya adalah klien cukup antusias dan kooperatif saat penulis melaksanakan pengkajian dan intervensi. Di sementara faktor yang menghambat adalah pada saat dilakukan implementasi penulis bisa melihat secara langsung efek dari pemberian aromaterapi lavender tersebut.

Evaluasi keperawatan klien pada diagnosa pertama, gangguan pola tidur masalah dapat teratasi sebagian dengan penerapan aromaterapi lavender. Hal ini didasarkan pernyataan klien bahwa sudah bisa memulai tidur pada malam hari dan bisa tidur siang walau hanya 1 jam. Ketika dilakukan monitoring tanda-tanda vital klien pada hari terakhir kunjungan didapatkan TD:130/80 mmHg, RR : 20 x/menit , N : 85 $\mathrm{X} /$ menit. Maka masalah gangguan pola 
tidur dan memberikan aromaterapi lavender telah selesai, dan intervensi dihentikan.

\section{UCAPAN TERIMA KASIH}

1. Ketua Yayasan Harapan Bunda

2. Rektor Institut Keseahatan mitra Bunda

3. Kepala Puskesmas Sungai Panas

\section{SARAN}

Melihat manfaat aroma terapi lavender ini dapat di manfaatkan sebagai terapi non farmakologis oleh pihak puskesmas untuk mengatasi insomnia yang di alami oleh lansia. Selain itu hasil dari intervensi pada asuhan keperawatan ini dapat menjadi referensi tentang pemanfaatan aroma terapi lavener untuk mengatasi insomnia. Penelitian selanjutnya diharapakan dapat mencari terapi non farmakologis lain untuk mengatasi insomnia.

\section{REFERENSI}

Adiyati, Sri (2010). Pengaruh aromaterapi terhadap insomnia pada lansia di PSTW unit budi luhur kasangan bantul Yogyakarta. Diunduh tanggal 12 november 2019 dari https://www.academia.edu/

Agusta, A (2012). Aromaterapy, Jakarta : penebar swadaya. Hal: 1-3, 45

Amin Huda dan hardi kusuma (2015). Aplikasi asuhan keperawatan berdasarkan diagnosa medis dan NANDA NIC NOC. Edisi Revisi jilid 3

Anggraini. (2009). Lavender aromatherapy improve quality of slep in elderly people. Di unduh tanggal 10 november $2019 \quad$ dari https://www.academia.edu/9494674/la vender__aromatherapy_improve _quality_of__sleep_in_alderly _people

Asmadi, R.Y. (2014). Buku ajar Asuhan Keperawatan Gerontik: Aplikasi NANDA, NIC dan NOC-jilid I.jakarta: $\mathrm{CV}$. Trans Info Medika

Buletin jendela Data \& informasi. Kemenkes RI. (2013). Gambaran kesehatan lanjut usia di Indonesia. Jakarta. Diunduh tanggal 08 november 2019 http://www.depkes.go.id/download.ph p/file=download/pusdatin/buletin/buleti n-lansia.pdf

Dewi, S.R. (2014). Buku ajar Keperawatan gerontik Yogyakarta. Deepublish

Dinas kesehatan provinsi kepulauan riau. (2016). Profil kesehatan kepulauan riau diunduh tanggal 02 november 2019 dari http//www.depkes.go.id/resources/dow nload/profil/PROFINSI_2016/10_kepri 2016.pdf

DISMENORE, PENGARUH AROMATHERAPY KAYU MANIS TERHADAP; PUTRI, PRIMER PADA REMAJA. Jurnal Akademi Farmasi Prayoga. Jurnal Akademi Farmasi Prayoga, 2020, 5.2.

Dinas kesehatan Kota Batam, kemenkes RI. (2016). Modul pelatihan pelayanan kesehatan lajut usia dan geriatric untuk petugas puskesmas. Kota Batam

Dinas kesehatan kota batam. (2017). Laporan kesehatan kelompok lanjut usia Tahun 2017. Kota Batam

Kementrian Kesehatan RI. (2013). Populasi lansia diperkirakan meningkat hingga tahun 2020. Diunduh tanggal 02 november 2012 . dari http://www.depkes.go.id/article/view/1 3110002/populasi-lansia-diperkirakanterus-meningkat-hingga-tahun2020.html

Kusnanto, dkk. (2007). Manfaat Aromaterapi lavender terhadap penurunan insomnia pada lansia diunduh tanggal 06 november 2019 dari

https://media.neliti.com/media/public ation/119497-ID-none.pdf

Lumbantobing. (2012). Gangguan tidur, Jakarta: Baloi penerbit FK-UI

Muhith, A,.\&siyoto, S. (2016). Pendidikan keperawatan gerontik: Yogyakarta CV. Andi OFFset

Nasrullah, D. (2016). Buku ajar keperawatan gerontik : jilid I gangguan pendekatan asuhan keperawatan NANDA NIC dan NOC. Jakarta : CV, Trans Info Medika

Nuraini. 2014. Aneka Manfaat Bunga Untuk Kesehatan. Yogyakarta: Gaya Media 
Nurarif, A.H,. \& kusuma, H. (2015).

Aplikasi suhan keperawatan

berdasarkan Diagnosa Medis \&

NANDA NIC-NOC.

Jogjakarta:mediaction

Nurhasanah, (2013). Aromaterapi.

Http://www.holistikaromaterapi.com.

Tanggal 02 desember 2006, jam

$15.50 \mathrm{wib}$

Ratnawati, E, (2017). Asuhan keperawatan

Gerontik. Jakarta: pustaka baru

Selamihardja, N,.(2009). Insomnia dan

Rahasia tidur nyaman,

http://www.indomedia.com. Tanggal

2 desember 2006, jam 16.00 wib

Sunaryo,. W. R. et. Al. (2015). Asuhan keperawatan gerontik. Yogyakarta

Stanhope, M., \& Lancaster, J. (2016). Public health nursing population centered health care in the community (9th Ed.). Missouri: Elsevier.

Tamher, S. N. (2009). Kesehatan usia lanjut dengan pendekatan asuhan keperawatan, Jakarta: selemba medika 
